\title{
Dakwah Bil Hal Melalui Hijab Mahasiswi Insuri Ponorogo Tahun 2017
}

\author{
Suwanti \\ Institut Agamna Islam Sunan Giri Ponorogo \\ suwantiok@gmail.com \\ Abstrak
}

Menutup aurat bagi seorang muslimah adalah kewajiban, Pakaian adalah salah satu kebutuhan dasarl hidup manusia melalui pakaian simbol-simbol budaya manual. Hijab bagian dari pakaian, hijab awalnya merupakan sebuah kewajiban agama namun kini terjadi pergeseran makna dan memandang hijab. Penelitian ini mengangkat masalah hijab ditinjau dari prespektif dakwah, khususnya pandangan mahasiswi INSURI Ponorogo terhadap hijab. penelitian ini menggunakan pendekatan fenomenologi.dari penelitian yang dilakukan bahwa tren hijab memang dirsa karena pengarus dari salah satu tokoh. Selain itu juga karena memang menjadi kewajiban oleh setiap muslim. Pengaruh dari tokoh ini yang lebih mendominasi dari adanya hijab. Hal ini disebutkan karena ingin meniru gaya tokoh tersebut.

Kata kunci: Dakwah Bil hal, Hijab Mahasiswi, tokoh

abstract

Covering the genitals for a Muslim woman is an obligation. Clothing is one of the basic needs of human life through manual cultural symbols clothing. Hijab is part of clothing, hijab was originally a religious obligation but now there is a shift in meaning and view of hijab. This study raises the issue of hijab in terms of the perspective of da'wah, especially the views of INSURI Ponorogo students on hijab. This study uses a phenomenological approach. From the research conducted, the hijab trend is indeed felt because of the influence of one of the characters. In addition, because it is an obligation by every Muslim. The influence of this figure is more dominating than the hijab. This is mentioned because they want to imitate the character's style.

Keywords: Bil Hal's Da'wah, Student Hijab, figures

\section{A. PENDAHULUAN}

Pada awalnya busana atau pakaian dipakai sebagai pelindung tubuh dari sengatan matahari dan rasa dingin saja. Jika kita bisa memahami seiring berkembangnya zaman, busana menjadi bagian penting dari hidup manusia karena mengandung unsur etika dan estetika dalam masyarakat. Terkadang seseorang bisa juga dinilai dari cara berbusananya, bagi kita muslimah berbusana tidak sekedar menutup tubuh, tetapi merupakan identitas sebagai muslimah yang bermartabat dan bermoral. Fungsi pakaian sebagai penutup aurat bukan sekedar penutup tubuh.(Bahtiar 2009) 
Bagi masyarakat modern, dakwah tidak hanya diartikan menyampaikan pesan kebaikan, tapi juga lebih mengarah kepada gerakan problem solving melalui hijab dan gaya hidup. Dakwah sebagai sesuatu yang identik dengan Islam itu sendiri. Sehingga segala aktifitas yang berkaitan dengan Islam dapat dikatakan sebagai aktifitas dakwah. Fenomena dakwah bil-hal yang diharapkan menjawab keresahan masyarakat terhadap permasalahan hijab dan gaya hidup, yakni tren berhijab.(anggraini : 2017)

Dakwah bil-hal merupakan aktifitas dakwah Islam yang dilakukan dengan tindakan nyata atau amal nyata terhadap kebutuhan penerima dakwah, sehingga tindakan nyata tersebut sesuai dengan apa yang dibutuhkan oleh kalangan masyarakat dan lingkup kampus INSURI ( Amin, 2009: 178). Dakwah bil-hal lebih aktif, dinamis, dan praktis melalui berbagai kegiatan dan pengembangan. Melalui dakwah model tersebut mahasiswi dan lingkungan kampus INSURI memiliki semangat keagamaan dalam mengetahui hijab dan gaya hidup menurut agama Islam.

Manusia modern membutuhkan model dan pendekatan dakwah yang dapat memecahkan masalah, yang lebih nyata dan langsung dapat dinikmati dan mengangkat harkat, martabat, dan kesejahteraan hidup manusia. Dakwah yang dimaksud harusnya dapat meningkatkan kesadaran diri (Religi) menjadi lebih baik. Dakwah tidak boleh jauh dari realitas sosial, seperti halnya bagaimana cara mengenakan hijab dalam beraktifitas dan gaya hidupnya. Sedangkan perintah hijab diperlihatkan dalam Al-Qur'an surat (Al-Ahzab: 59) yang artinya :

"Wahai Nabi, katakanlah kepada istri-istrimu, anak perempuanmu dan istri-istri orang mukmin, 'Hendaklah mereka menutupkan jilbabnya keseluruh tubuh mereka'. Yang demikian itu agar mereka lebih mudah untuk dikenali, sehinggga mereka tidak diganggu. Dan Allah Maha pengampun dan Maha penyayang”.

Fenomena jilbab selalu muncul dengan berbagai ekspresi dan pesan dibelakangnya, Apalagi, seiring perkembangan ilmu pengetahuan (misalnya, isu gender dan feminisme), jilbab menjadi wacana yang selalu hangat diperbincangkan dan menjadi kontroversi. Salah satu dampak penggunaan jilbab ini adalah maraknya pemakaian jilbab untuk acara-acara tertentu baik formal maupun non formal. Orang tidak takut lagi memakai jilbab bahkan tidak hanya untuk menghadiri acara keagamaan. Di pasar, terminal, sekolah, perkantoran, bank bahkan rumah 
makan fast food-pun dengan mudah kita bisa temui perempuan berjilbab seolah-olah jilbab telah menjadi bagian dari kehidupan.

Mahasiswa adalah sebagai generasi pengganti dan berperan untuk perubahan yang lebih baik. Mahasiswa juga memberikan dampak bagi masyarakat di lingkungannya dan Institutnya. Sebagian besar masyarakat mulai beramai-ramai memakai jilbab. Begitu juga dengan mahasiswi di Ponorogo yang tidak ketinggalan untuk memakai jilbab. Aturan pemakaian jilbab begitu saja diabaikan, hal ini akhirnya mendorong pemakaian jilbab sebagai sebuah fantasi kenikmatan bentuk lain dari berpakaian. Jilbab tidak menjadi simbol identitas keimanan tetapi bagian dari aksesoris berpakaian. Sejak itu, jilbab pun menjadi trend. Dengan kata lain, pakaian muslimah (jilbab) dapat dianggap mampu mengkomunikasikan hasrat menjadi orang modern yang saleh dan sekaligus menjadi muslim yang modern karena mengikuti trend. Akhirnya bagi orang-orang tertentu, jilbab itu menjadi bagian dari gaya hidup yang menandakan modernitas. Gaya hidup modern adalah segala-galanya. Tidak peduli apakah itu bagian dari keutamaan untuk mentaati aturan agama atau hanya menjadi kamuflase ketaatan semata. Gaya busana dengan berjilbab bagi mahasiswi di Ponorogo sudah menjadi fenomena yang harus terus diikuti agar tidak dikatakan ketinggalan tren yang selalu berubah-ubah.

\section{B. Metode penelitian}

Dalam suatu penelitian diperlukan adanya suatu metode yang digunakan untuk menyelesaikan suatu laporan penelitian yang dilakukan. Dalam penelitian ini metode-metode yang digunakan adalah sebagai berikut: penelitian ini pendekatan yang dilakukan adalah melalui pendekatan Sosiologi kualitatif. Arti pendeketan kualitatif adalah data yang dikumpulkan bukan berupa angka-angka, melainkan data tersebut dari naskah wawancara. Krik dan Miller memberikan pengertian penelitian kualitatif sebagai tradisi penelitian yang tergantung pada pengamatan sesuai dengan orang-orang di sekitar objek dalam bahasa dan peristilahan sendiri (Moleong, 2009).

Penelitian ini dilaksanakan dengan menggunakan metode kualitatif yang berarti metode yang digunakan untuk meneliti kondisi objek yang alamiah, dimana peneliti sebagai instrumen kunci, teknik pengumpulan data dilakukan secara gabungan, analisis data bersifat induktif, dan hasil penelitian kualitatif dan lebih menekankan pada generalisasi. Sebagaimanatelah 
dikemukakan oleh Fatimah Djajasudarma mengenai metode kualitatif, metode ini merupakan prosedur yang menghasilkan data deskriptif berupa data tertulis atau lisan dari suatu masyarakat. Penelitian ini bersifat deskriptif, yakni menjelaskan atau mengungkapkan suatu masalah dan keadaan sebagaimana adanya (Djajasudarma, 2006).

\section{Hasil Penelitaian}

Pada dasarnya pakaian yang dikehendaki Islam adalah yang tidak tipis, dan tidak ketat hingga kelihatan lekuk-lekuk postur tubuh. Pakaian yang tipis, yang tembus pandang, apabila dipakai oleh seorang wanita, maka akan dikenakan saksi. Sahabat Abi Hurairah menegaskan, bahwa Rasulullah telah bersabda : "Ada dua golongan manusia yang menjadi penduduk neraka, yang aku belum pernah melihatnya : Sekelompok kaum yang membawa cemeti seperti ekor sapi yang digunakan untuk memukul manusia. Dan sekelompok wanita yang berpakaian tipis tembus pandang, membuka cadar, lenggak-lenggok dalam berjalan, dan bersanggul hingga tampakdi kepala mereka bagaikan punuk unta yang miring. Mereka tidak akan masuk surga dan tidak akan mencium bau surga, padahal bau surga itu dapat dicium dari kejauhan sejauh perjalanan tertentu. “( HR. Muslim dari Abi Hurairah ).

Pakaian tembus pandang adalah pakaian yang tidak menutup seluruh tubuh sehingga masih nampak postur tubuhya, seperti lengan, dada, dan leher. Atau, mengenakan pakaian dari bahan yang tipis, hingga kulit tubuhnya masih kelihatan. Yang demikian bisa dikatan berpakaian tapi tetap telanjang. Karena itu, seyogyanya apabila wanita mengenakan pakaian hendaklah yang longgar, jangan yang ketat hingga kelihatan menonjol lekuk-lekuk tubuhnya.

Informan pertama mengatakan, Hijab adalah kewajiban dan suatu kebutuhan yang harus dikerjakan, dalam Agama Islam bahwa seorang muslimah wajib untuk memakai hijab. Kedua, Hijab adalah bentuk yang menjadikan kebiasaan yang indah dan bisa menjaga diri. Ketiga, Hijab mencerminkan perilaku di lingkungan, atau dalam suatu forum yang bisa sebagai cerminan dan memberikan kenyamanan. Meski sudah banyak mode-mode hijab, akan tetapi tampilan hijab dipakai simpel dan menyesuaikan dengan busana, yang terpenting longgar. Keempat, Hijab yang dipakai harus pantas dipakai sebagai seorang muslimah, jangan mudah terpengaruh ingin tampil beda dari yang lain, yang akibatnya merugikan diri sendiri karena kita selalu memperhatikan memakai hijab. Kelima, Hijab modis namun tetap syar'i. Keenam, Hijab 
adalah kewajiban dan memiliki manfaat untuk dirinya juga sebagai dakwah untuk mengajak mereka yang belum berhijab akhirnya mau berhijab. Ketujuh, Hijab menjaga mertabat seorang muslimah, penutup yang melindungi pandangan dari laki-laki.

Pada masa pra Islam, konsep hijab telah dikenal pada beberapa agama dan budaya masyrakat. Misalnya pada ajaran Majusi, Yahudi dan Nasrani serta pada kebudayaan Romawi, Persia dan Hindia. Sedangkan pada masyarakat Arab, tradisi hijab baru dikenal ketika datangnya Islam. Menurut Will Durant seorang penulis buku The Story of Civilization dalam buku Wanita dan Hijab karya Sayyid Murtada Mutahhari pada masyarakat persia, budaya hijab baru diterapkan pada masa pemerintahan Daryusy, namun penggunaannya hanya terbatas pada waita yang sedang haid.(Zulfikar : 2017)

Aturannya adalah setiap wanita yang sedang haid harus mengenakan kerudung jika hendak keluar rumah. Hal ini di pengaruhi oleh aturan yang diterapkan pada kaum Majusi terdahulu. Menutup aurat adalah dengan menggunakan kain atau pakaian yang berfungsi sebagai penghalang (penghambat) pandangan terhadap aurat terbuka. Dalam pandangan Islam, perempuan memiliki tempat dan kedudukan terhormat sehingga mereka memiliki tanggung jawab yang sama dengan laki-laki. Penghormatan Islam terhadap perempuan adalah dengan disyari'atkannya jilbab bagi para muslimah, karena dengan demikian kaum perempuan tidak menjadi bahan tontonan terhadap kaum laki-laki yang bukan mahromnya.

Berhijab bukan asal sesuai dengan tren masa kini dan tidak menjadi bagian dari perhiasan, melainkan harus sesuai dengan Al-Qur'an dan sunah seperti menutup seluruh tubuh kewajiban perempuan muslimah menutup auratnya dengan sempurna. Aturan berhijab yang sesui dengan syari'at Islam adalah longgar dan tidak ketat, pakaian yang longgar yang tidak ketat dimaksudkan tidak menampakkan bagian lekuk tubuhnya. Menggunakan kain tebal yaitu kain yang tidak tipis dan transparan. Pada zaman Nabi Muhammad saw, hijab yang tipis sangat tidak diperbolehkan karena hal itu sama saja tidak berhijab. Aturan tidak menyerupai laki-laki, Dari Abu Hurairah: "Rasulullah saw, melatnat laki-laki yang memakai pakaian wanita dan wanita yang memakai pakaian laki-laki." (HR Abu Dauddan Ahmad).

Dari sekian banyak ayat Al-Qur'an yang berbicara mengenai pakaian, beberapa fungsi pakaian atau pesan dakwah yang terdapat dalam busana, diantaranya sebagai perhiasan, 
memelihara pemakaianya dari sengatan matahari dan dinginya udara dan dari segala yang mengganggu jasmani, serta sebagai petunjuk identitas pembeda seseorang dengan lainnya.

Hijab memberikan makna bagi mahasiswi untuk memberikan pengertian bagi masyarakat awam, hingga remaja dan mahasiswi lain, yang belum memahahami makna hijab untuk Agama Islam. Dalam Ajaran Islam sudah sering kali diterangkan dan dibahas dalam babbab sebelumnya berhijab adalah kewajiban, juga sebagai benteng pengamanan untuk perempuan, melindungi kehormatan. Islam memberikan banyak manfaat terhadap semua muslim dan muslimah, seperti halnya umat Islam memiliki identitas dan pengaruh besar, identitas seorang muslimah adalah mampu menutup auratnya mengenakan pakaian yan longgar. Bukan karena hanya untuk sekedar mencoba berhijab tapi, setelah itu dilepas kembali dan tidak mengenakan hijabnya. Kewajiban berhijab sudah wajib hukumnya bagi seorang muslimah. Mahasiswi kini semakin pandai dan tren jika mengenakan hijab, namun jangan sampai berhijab tetapi telanjang. Mahasiswi punya banyak kesempatan untuk terus belajar dan mengembangkan budaya berhijab yang syar'i namun tetap modis dan elegan, agar sipapun yang memandang tidak menilai kita hanya ingin cari perhatian atau dipuji. Sebab berhijab bukan untuk menjadi ajang bergaya tapi sebagai modal untuk menjauhkan pintu neraka, karena wanita yang tidak berhijab adalah wanita yang kelak akan menghuni neraka. Sebagai mahasiswi yang kuliah di kampus NU, berikanlah motifasi untuk mereka yang belum bisa berhijab dengan dorongan dari hati dan akan terus memakainya, bukan karena terpaksa ingin memakai hijab. ketika berhijab juga harus disesuikan dengan tingkah laku dan kesehariannya, jangan sampai berhijab tetapi tingkah laku kita tidak mencerminkan seorang muslimah. Mahasiswa harus pandai berpendapat ketika mengajak muslimah untuk menjalankan kewajiban berhijab. Bisa di katakan bahwa idwentitas muslimah adalah berhijab dan berpakaian menurut syari'at Islam, dan berhijab adalah kewajiban.

Dakwah bil hal bagi mahasiswi yang berhijab bisa dijadikan sebuah kelompok, dan membuat sebuah komunitas, untuk belajar bersama bagaimana berhijab yang sesuia syari'at agama Islam, dan sebagai simbol muslimah. Berhijab memberikan pandangan baik bagi mereka yang ingin lebih dalam mengetahui hijab, dalam komunitas tersebut akan banyak manfaat yang bisa di dapat diantaranya, bagaimana Islam memuliakan seorang wanita muslimah, berhijab adalah kehormatan wanita yang wajib dijaga, identitas yang berkarakter. 
Dari hasil wawancara mengenai Tren hijab di kalangan mahasiswi INSURI Ponorogo, setiap wanita muslim pastinya menginginkan dirinya menjadi wanita yang selalu taat dan patuh kepada perintah agama, adalah berhijab. Menjadi wanita yang shalehah adalah dambaan setiap wanita muslim.(Hidayanti : 2017) Namun, pada penerapannya tidaklah mudah. Mahasiswi INSURI mereka berada pada lingkungan dan latar belakang pendidikan yang sama, tetapi menjadi taat pada agama atau tidak itu kembali pada diri mereka masing-masing. Keanekaragaman bentuk hijab yang mereka gunakan sangat bervariasi, sesuai dengan model apa yang diinginkan mahasiswi tersebut.

Saat ini banyak public figure perempuan yang mengenakan hijab, bukah hanya memakai hijab akan tetapi mereka telah membuat trobosan pada gaya hijab, seperti halnya penggunaan ciput yang dipopulerkan oleh Marshanda, Dewi Sandra dengan jilbah "Hana" yang dibuat oleh artis Zaskia Adia Mecca dan hijab panjang yang dikenakan oleh Oki Setiana Dewi yang selalu ia pakai kemanapun. Ada pula dari kalangan desainer yaitu Dian Pelangi yang membawa hijab dapat dikenal sampai dunia internasionel. Darikalangan penulis yaitu Asma Nadia yang telah mengeluarkan banyak buku bernuansa Islam dengan tema yang dapat diterima kalangan manapun. Hal ini membuktikan bahwa hijab yang mereka gunakan bukan menjadi penghalang bagi para muslimah untuk berkarya dan melakukan aktivitas mereka. Hal tersebut menegaskan pada masyarakat bahwa hijab bukan hal yang tabu, bukan lagi penghalang bagi kaum muslimah untuk tetap berkarya. Dengan munculnya tren model hijab mahasiswi dapat memberikan arahan kepada pemula ketika akan mengenakan hijab, mahasiswi juga harus pandai memahami mana yang baik dan syar'i mengenakan hijab dan mana yang merusak nilai identitas wanita muslimah berhijab.

\section{Kesimpulan}

Berdasarkan hasil penelitian dan pembahasan yang telah peneliti sampaikan, tentang Dakwah bi al-hal Melalui Hijab Mahasiswi INSURI Ponorogo Tahun 2017, penulis mendapatkan data-data yang kemudian dianalisis dan diuraikan maka ada beberapa hal yang dapat penulis tarik sebagai kesimpulan.

Dari hasil penelitian yang penulis lakukan dari beberapa informan Mahasiswi INSURI Ponorogo, yang secara keseluruhan berjumlah tiga belas responden yang diambil dari semester 1 
sampai semester 9, angkatan 2013-2016. Adapun kesimpulannya yaitu : Bahwa mahasiswi INSURI secara umum cukup memahami tentang makna hijab dan memahami batasan aurat seorang wanita. penggunaan hijab yang mereka kenakan tetap menutupi aurat dan syar'i. Pertama, menggunakan hijab trendy ( persegi empat, phasmina, penuh corak dan full colour) karena dianggap lebih mudah dipakai. Kedua, mengikuti tren berhijab dari public figure, misalnya saja, segi empat dari artis Laudya Cynthia Bella, phasmina artis Fatin Sidqia Lubbis, namun ada yang mengikuti tren hijab dan tetap syar'i yaitu artis Oki Setiana Dewi.

\section{DAFTAR PUSTAKA}

Bahtiar, Sutan Deni, Berjilbab dan Tren Buka Aurat, Mitra Pustaka, Yogyakarta 2009. Samihah, Dr dan Badriyah Usth, Yuk, Sempurnakan Hijab, Aisar Publising, Solo 2014. Sugihanto, H. Dr, Pedoman Penulisan Skripsi, Lp2m, Ponorogo 2011. Arikunto, Suharsimi, Prosedur Penelitian Suatu Pendekatan Praktek, Jakarta: Rineka Cipta 1996.

Al-Mahali, Abu Iqbal, Muslimah Modern, Mitra Pusaka, Yogyakarta 2000. Agus R, Abu Hasan, Pendekatan Antropologi Dalam Studi Islam, 2000.

Atik Catur Budiati, Jilbab: Gaya Hidup Baru Kaum Hawa, Jurnal Sosiologi Islam. Vol 1 No. 1. 2011.

Ahmad Suhendra, Kontestasi Identitas Melalui Pergeseran Interpretasi Hijab dan Jilbab Dalam Al-Qur'an, Palastren. Vol 6 No. 1. 2013.

El-Guindi Fadwa, Jilbab Antara Kesalehan, Kesopanan dan Perlawanan, Serambi, Jakarta 2016.

Meitia Rosalina Yunita Sari, Jilbab Sebagai Gaya Hidup Wanita Modern, Universitas Sunan Kalijaga, Yogyakarta 2016.

Jasmani, Hijab dan Jilbab Menurut Hukum Fikih, Jurnal Al-`Adi. Vol 6 No. 2. Juli 2013.

Li Patrick, Jilbab Bukan Jilboob, Penerbit Kalil, Jakarta 2014.

Yasinta Fauziah Novitasari, "Jilbab Sebagai Gaya Hidup : (Studi Fenomenologi Tentang Alasan Perempuan Memakai Jilbab dan Aktifitas Solo Hijabers Community)”. Prodi Pendidikan Sosiologi Antropologi FKIP UNS. 2014.

Diah Ainin Budiarti, Sarmini, "Gaya Berbusana Mahasiswi Pengguna Jilbab Pemula di Fakultas Ilmu Sosial UNESA”, Kajian Moral dan Kewarganegaraan. No. 3. Vol. 3. 2015.

Arik Dwiyantoro, Sugeng Harianto, Fenomenologi Gaya Hidup Mahasiswa UNESA Pengguna Pakaian Bekas. Universitas Negri Surabaya, 2014.

Sinung Utami Hasri Habsari, "Fashion Hijab Dalam Kajian Budaya Populer", Jurnal PPKM II 2015.

Istiqomah, "motivasi berhijab mahasiswa (studi kasus mahasiswa STAIN Salatiga semester 1 dan 7), Skripsi jurusan Pendidikan Agama Islam, Sekolah Tinggi Agama Islam Negeri Salatiga (STAIN) 2013.

Asni Djemerang dan Zulfikar, "Peran Komunitas Hijabers Moslim Makassar dalam Memotifasi Muslimah Berhijab", Jurnal Al-Khitabah, Vol. III, No. 1, 2017.

Nur Silvia Hidayanti, "Tren Model Berjilbab di Kalangan Mahasiswi Komunikasi dan Penyiaran Islam Institut Agama Islam Negeri Purwokerto," Prodi Komunikasi dan Penyiaran Islam. Institut Agama Islam Negeri Purwokerto. 2017. 
Rayendar, Metode Penelitian Menurut Sugiyono 2013. http// blogspot.co.id/2015/06. Diakses 7 februari 2017.

http:// dunia-penelitian.blogspot.co.id/2011/10/pengertian-teknik-wawancara-observasi/,. diakses 6 februari 2017.

http://pastiguna.com/teknik-analisis-data/,. 